
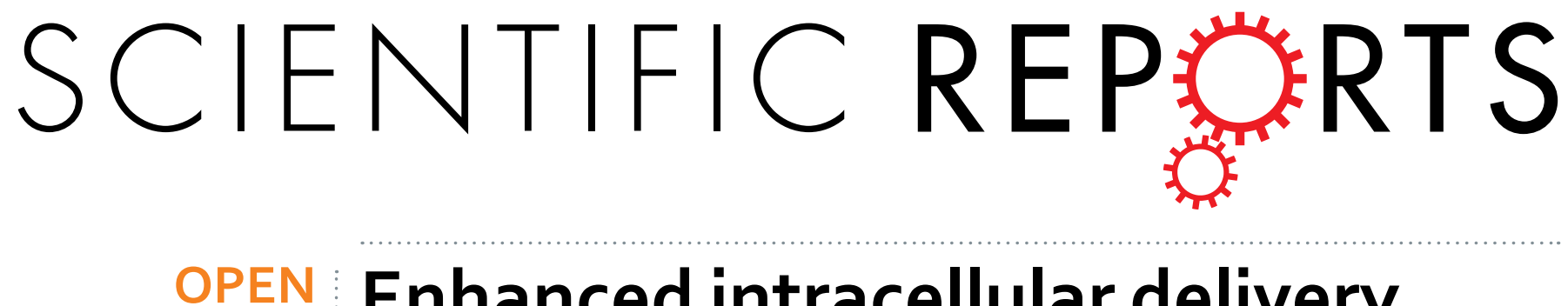

\title{
Enhanced intracellular delivery and antibacterial efficacy of enrofloxacin-loaded docosanoic \\ acid solid lipid nanoparticles against intracellular Salmonella
}

Received: 23 August 2016

Accepted: 15 December 2016

Published: 23 January 2017

\author{
Shuyu Xie ${ }^{1, *}$, FeiYang ${ }^{1, *}$, Yanfei Tao ${ }^{2}$, Dongmei Chen ${ }^{2}$, Wei Qu ${ }^{1}$, Lingli Huang ${ }^{1}$, Zhenli Liu ${ }^{2,3}$, \\ Yuanhu $\operatorname{Pan}^{1}$ \& ZonghuiYuan ${ }^{1,2,3}$
}

Enrofloxacin-loaded docosanoic acid solid lipid nanoparticles (SLNs) with different physicochemical properties were developed to enhance activity against intracellular Salmonella. Their cellular uptake, intracellular elimination and antibacterial activity were studied in RAW 264.7 cells. During the experimental period, SLN-encapsulated enrofloxacin accumulated in the cells approximately 27.0637.71 times more efficiently than free drugs at the same extracellular concentration. After incubation for $0.5 \mathrm{~h}$, the intracellular enrofloxacin was enhanced from 0.336 to $1.147 \mu \mathrm{g} / \mathrm{mg}$ of protein as the sizes of nanoparticles were increased from 150 to $605 \mathrm{~nm}$, and from 0.960 to $1.147 \mu \mathrm{g} / \mathrm{mg}$ of protein when the charge was improved from $-\mathbf{8 . 1}$ to $-\mathbf{2 4 . 9} \mathrm{mv}$. The cellular uptake was more significantly influenced by the size than it was by the charge, and was not affected by whether the charge was positive or negative. The elimination of optimal SLN-encapsulated enrofloxacin from the cells was significantly slower than that of free enrofloxacin after removing extracellular drug. The inhibition effect against intracellular Salmonella CVCC541 of 0.24 and $0.06 \mu \mathrm{g} / \mathrm{mL}$ encapsulated enrofloxacin was stronger than $0.6 \mu \mathrm{g} / \mathrm{mL}$ free drug after all of the incubation periods and at $48 \mathrm{~h}$, respectively. Docosanoic acid SLNs are thus considered as a promising carrier for intracellular bacterial treatment.

Salmonellae are Gram-negative bacilli that cause enteric diseases in a wide range of animals. They are typically acquired by the ingestion of contaminated food or water. Moreover, exposure to bacteria-infected animals can also pose a high risk of salmonellosis in humans ${ }^{1}$. It was reported that approximately 1.2 million people are infected with Salmonella spp. annually in the United States ${ }^{2,3}$. Salmonella spp. are facultative intracellular bacteria and have evolved many mechanisms to evade the phagocytic killing mechanism of the mammalian host and establish specialized intracellular niches, sequestered from the host immune system, to produce a chronic carrier state $^{4}$. Therefore, salmonellosis is difficult to treat because most of the available antimicrobial drugs (e.g., penicillins, cephalosporins and aminoglycosides) exhibit poor cellular diffusion and intracellular retention ${ }^{5}$.

Enrofloxacin, a second generation of fluoroquinolones, is used as a veterinary medicine for the treatment of salmonellosis because of its strong antibacterial properties and effective diffusion across cells ${ }^{6}$. However, it has low retention performance in host cells when the extracellular concentration decreases. It was observed that cells with accumulated enrofloxacin released about $80-90 \%$ of the drug within 10 min after being placed in enrofloxacin-free medium ${ }^{6}$. This problem results in treatment failure, drug resistance, high incidence of relapse, and drug-induced organ toxicity with repeated, high doses of treatment. Therefore, the intracellular clearance of Salmonella, mainly in macrophages, requires novel therapeutic strategies.

${ }^{1}$ National Reference Laboratory of Veterinary Drug Residues (HZAU), Huazhong Agricultural University, Wuhan, Hubei 430070, China. ${ }^{2}$ MOA Laboratory for Risk Assessment of Quality and Safety of Livestock and Poultry Products, Huazhong Agricultural University, Wuhan, Hubei 430070, China. ${ }^{3}$ MAO Key Laboratory for Detection of Veterinary Drug Residues, Huazhong Agricultural University, Wuhan, Hubei 430070, China. *These authors contributed equally to this work. Correspondence and requests for materials should be addressed toY.P. (email: panyuanhu@mail.hzau. edu.cn) or Z.Y. (email: yuan5802@mail.hzau.edu.cn) 


\begin{tabular}{|c|c|c|c|c|c|c|c|}
\hline \multicolumn{2}{|c|}{ Surfactant } & \multirow[b]{2}{*}{$\begin{array}{l}\text { Probe Sizes } \\
(\mathrm{mm})\end{array}$} & \multirow[b]{2}{*}{ MD (nm) } & \multirow[b]{2}{*}{ PDI } & \multirow[b]{2}{*}{$\mathbf{Z P}(\mathbf{m v})$} & \multirow[b]{2}{*}{ EE (\%) } & \multirow[b]{2}{*}{ LC (\%) } \\
\hline $\begin{array}{l}\text { PVA } \\
\text { concentration }\end{array}$ & $\begin{array}{l}\text { PVA volume } \\
(\mathrm{mL})\end{array}$ & & & & & & \\
\hline $1 \%$ & 10 & 3 & $605.0 \pm 4.9$ & $0.241 \pm 0.076$ & $-24.9 \pm 0.7$ & $95.9 \pm 1.6$ & $9.3 \pm 0.2$ \\
\hline $2 \%$ & 20 & 6 & $414.5 \pm 3.8^{\mathrm{a}}$ & $0.265 \pm 0.019$ & $-22.1 \pm 0.1^{\mathrm{a}}$ & $86.6 \pm 1.7^{\mathrm{a}}$ & $8.6 \pm 0.2$ \\
\hline $4 \%$ & 30 & 30 & $150.1 \pm 1.9^{\mathrm{a}}$ & $0.184 \pm 0.018^{b}$ & $-13.1 \pm 1.0^{\mathrm{a}, \mathrm{b}}$ & $59.2 \pm 3.5^{\mathrm{a}}$ & $5.8 \pm 0.4^{\mathrm{a}, \mathrm{b}}$ \\
\hline
\end{tabular}

Table 1. Physicochemical characteristics of enrofloxacin-loaded docosanoic acid SLNs with different polyvinyl alcohol concentration and preparation process $($ mean \pm S.D., $\mathbf{n}=3)$. EE: Encapsulation efficiency; LC: Loading capacity; MD: Mean diameter; PDI: Polydispersity index; ZP: Zeta potential. ${ }^{\text {aStatistical }}$ significances compared with $1 \%$ PVA are $\mathrm{p}<0.05$. ' Statistical significances compared with $2 \%$ PVA are $\mathrm{p}<0.05$.

Nanocarriers have the ability to accumulate in macrophages and other cells, which makes them potentially useful for the treatment of intracellular infections, including Salmonella ${ }^{5}$. In this respect, liposomes and polymeric nanoparticles have been reported to be effective carriers, increasing the intracellular accumulation of fluoroquinolones at the site of infection with reduced toxicity and side effects. Liposomal enrofloxacin was reportedly delivered to Anatolian shepherd dog monocytes, resulting in the more effective treatment of intracellular infections than when free drugs were used ${ }^{7,8}$. Multilamellar liposome encapsulated enrofloxacin, which contained cholesterol and dipalmitoyl phosphatidylcholine in a molar ratio of 1:1.2, also produced a higher concentration in Kangal dog blood cells and was a more effective treatment for intracellular Staphylococcus aureus infections than solution ${ }^{9}$. In another study, liposomes composed of $15 \mathrm{mg}$ egg phosphatidylcholine and $35 \mathrm{mg}$ cholesterol resulted in increased activity of enrofloxacin against $S$. aureus in Turkish shepherd dog neutrophils ${ }^{10}$.

The properties of nanoparticles could greatly affect the intracellular delivery and efficacy of treatments. Ciprofloxacin nano-niosomes of 300-600 nm were more phagocytosed by macrophages than vesicles of 160$300 \mathrm{~nm}$ and $600-1000 \mathrm{~nm}^{11}$, while another study revealed that the delivery efficacy of ciprofloxacin-loaded liposomes to rat alveolar macrophages after pulmonary administration was enhanced by an increase in particle size from 100 to $1000 \mathrm{~nm}$ and became constant over $1000 \mathrm{~nm}^{12,13}$. The surface charge is also thought to be one of the most important factors in determining the intracellular behavior of nanoparticles and their encapsulated drugs ${ }^{14}$. Therefore, the investigation of common and decisive characteristics of nanoparticles in mediating cellular uptake is very important in the development of nanoparticle carriers.

Solid lipid nanoparticles (SLNs), an alternative drug carrier system to liposomes and polymeric nanoparticles, have attracted increasing attention due to their biocompatibility, biodegradability, stability, low cost and ease of large scale production ${ }^{15}$, and thus might be a promising carrier for the treatment of intracellular infections. Our previous study showed that fatty acid SLNs were effective nanoparticle systems for the controlled release and enhanced bioavailability of enrofloxacin in mice ${ }^{15}$. In this study, a series of enrofloxacin-loaded docosanoic acid SLNs of different sizes and zeta potentials were prepared by using a hot homogenization and ultrasonication method. The influence factors of intracellular delivery efficacy of enrofloxacin-loaded docosanoic acid SLNs were studied to obtain the optimum SLNs, and the antibacterial activity of the satisfactory nanoparticles was evaluated using the intracellular Salmonella infection model.

\section{Results}

Physicochemical characteristics of different docosanoic acid SLNs. The preparation process and properties of the surfactant had a significant impact on the physicochemical characteristics of docosanoic acid SLNs. The mean size of docosanoic acid nanoparticles decreased from 605.0 to $150.1 \mathrm{~nm}$ as Polyvinyl alcohol (PVA) concentrations, aqueous phase volumes and the ultrasound probe diameter were increased from 1 to $4 \%$, 10 to $30 \mathrm{~mL}$ and 3 to $30 \mathrm{~mm}$, respectively (Table 1 and Fig. 1). The polydispersity index (PDI) ranged from 0.184 to 0.265 when PVA concentration was increased from $1 \%$ to $4 \%$. The different charge of docosanoic acid nanoparticles was achieved by using varied concentrations of dimethyldioctadecyl ammonium chloride (DDAC) solution (Table 2). The zeta potential changed from -22.1 to $18.8 \mathrm{mv}$ as the DDAC concentration was increased from 0 to $4 \%$.

Cellular uptake of encapsulated enrofloxacin. The accumulation of encapsulated and free enrofloxacin in cells exhibited a clear and significant difference (Fig. 2) after exposure to RAW 264.7 cells for an increasing length of time. Encapsulated enrofloxacin achieved a concentration of $0.825 \mu \mathrm{g} / \mathrm{mg}$ of protein within $15 \mathrm{~min}$ and continued to accumulate intracellularly to a maximum concentration of $0.886 \mu \mathrm{g} / \mathrm{mg}$ of protein after $0.5 \mathrm{~h}$, while the free enrofloxacin reached a maximum intracellular concentration of $0.031 \mu \mathrm{g} / \mathrm{mg}$ of protein at $15 \mathrm{~min}$.

Effect of size on the cellular uptake of encapsulated enrofloxacin. The enrofloxacin in RAW 264.7 cells was enhanced by an increase in the particle sizes of docosanoic acid SLNs, when incubated for $0.5 \mathrm{~h}$. Docosanoic acid nanoparticles of 605, 415, and $150 \mathrm{~nm}$ resulted in intracellular enrofloxacin concentrations of $1.147,0.834$ and $0.336 \mu \mathrm{g} / \mathrm{mg}$ of protein, respectively (Fig. 3).

Effect of zeta potential on the cellular uptake of enrofloxacin. The zeta potential of docosanoic acid SLNs influenced the uptake of entrapped enrofloxacin in RAW 264.7 cells after an experimental period of $0.5 \mathrm{~h}$ (Fig. 4). The intracellular enrofloxacin decreased from 1.147 to $0.960 \mu \mathrm{g} / \mathrm{mg}$ of protein due to a decrease in the absolute value of the nanoparticle surface charge from 24.9 to $8.1 \mathrm{mv}$ when the cells were incubated with nanoparticles of equivalent size. The intracellular delivery efficacy of $7.1 \mathrm{mv}$ nanoparticles with an average size 

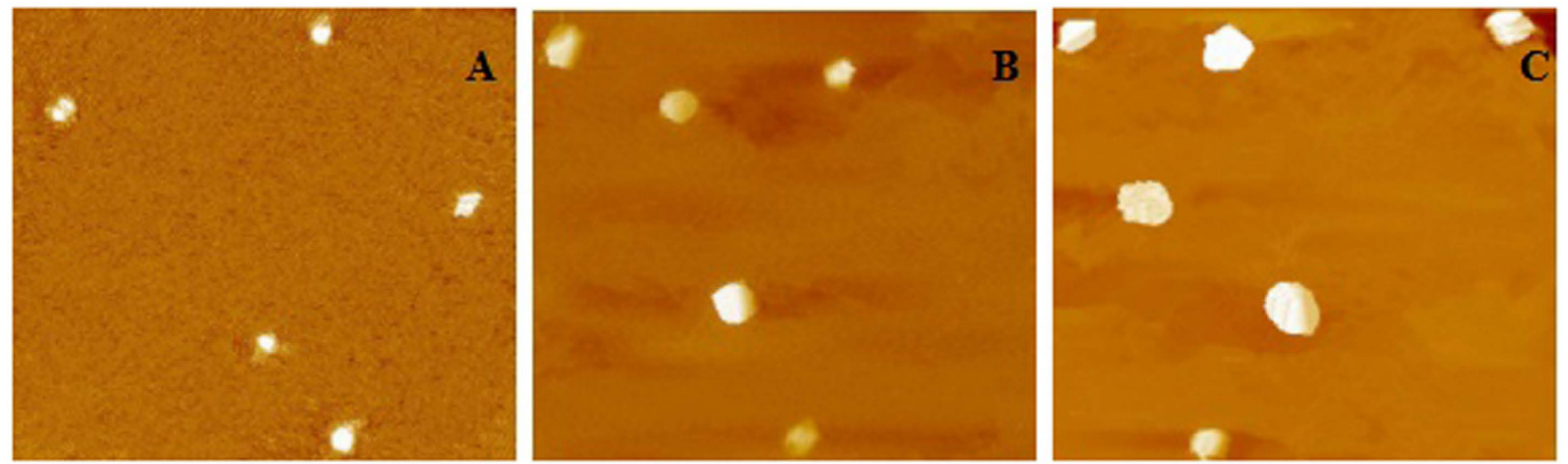

Figure 1. Photographs of atomic force microscopy (AFM) of different size of docosanoic acid SLNs $(5 \mu \mathrm{m} \times \mathbf{5} \mu \mathrm{m})$. (A) SLNs were prepared with $0.2 \mathrm{~g}$ enrofloxacin, $1.8 \mathrm{~g}$ docosanoic acid, and $30 \mathrm{ml} 4 \%$ PVA by using $30 \mathrm{~mm}$ sonication probes with $80 \%$ amplitude; (B) SLNs were prepared with $0.2 \mathrm{~g}$ enrofloxacin, $1.8 \mathrm{~g}$ docosanoic acid, and $20 \mathrm{ml} 2 \%$ PVA by using $6 \mathrm{~mm}$ sonication probes with $60 \%$ amplitude; (C) SLNs were prepared with $0.2 \mathrm{~g}$ enrofloxacin, $1.8 \mathrm{~g}$ docosanoic acid and $10 \mathrm{ml} 1 \%$ PVA by using $3 \mathrm{~mm}$ sonication probes with $60 \%$ amplitude.

\begin{tabular}{|c|c|c|c|c|c|c|c|}
\hline \multicolumn{2}{|l|}{ Surfactant } & \multirow[b]{2}{*}{$\begin{array}{c}\text { Probe Sizes } \\
(\mathrm{mm})\end{array}$} & \multirow[b]{2}{*}{ MD (nm) } & \multirow[b]{2}{*}{ PDI } & \multirow[b]{2}{*}{$\mathrm{ZP}(\mathbf{m v})$} & \multirow[b]{2}{*}{ EE (\%) } & \multirow[b]{2}{*}{ LC(\%) } \\
\hline Concentration & $\begin{array}{c}\text { Volume } \\
(\mathrm{mL})\end{array}$ & & & & & & \\
\hline $2 \% \mathrm{PVA}$ & 20 & 6 & $414.5 \pm 3.8$ & $0.265 \pm 0.019$ & $-22.1 \pm 0.1$ & $86.6 \pm 1.7$ & $8.6 \pm 0.2$ \\
\hline $2 \% \mathrm{PVA}+0.5 \% \mathrm{DDAC}$ & 20 & 6 & $617.5 \pm 7.1^{\mathrm{a}}$ & $0.458 \pm 0.010^{\mathrm{a}}$ & $-17.5 \pm 0.6^{\mathrm{a}}$ & $42.8 \pm 2.3^{\mathrm{a}}$ & $4.4 \pm 0.2^{\mathrm{a}}$ \\
\hline $2 \% \mathrm{PVA}+2 \% \mathrm{DDAC}$ & 20 & 6 & $532.1 \pm 10.0^{\mathrm{a} b}$ & $0.461 \pm 0.058^{\mathrm{a}}$ & $-8.1 \pm 0.4^{\mathrm{a}, \mathrm{b}}$ & $41.2 \pm 0.8^{\mathrm{a}}$ & $4.3 \pm 0.1^{\mathrm{a}}$ \\
\hline $2 \% \mathrm{PVA}+3 \% \mathrm{DDAC}$ & 20 & 6 & $501.3 \pm 16.6^{\mathrm{a}}$ & $0.417 \pm 0.016^{\mathrm{a}}$ & $7.1 \pm 0.5^{\mathrm{a}, \mathrm{b}, \mathrm{c}}$ & $46.7 \pm 2.4^{\mathrm{a}}$ & $4.8 \pm 0.3^{\mathrm{a}}$ \\
\hline $2 \% \mathrm{PVA}+4 \% \mathrm{DDAC}$ & 20 & 6 & $345.2 \pm 9.6^{\mathrm{a}, \mathrm{b}, \mathrm{cd}}$ & $0.393 \pm 0.011^{\mathrm{a}, \mathrm{b}}$ & $18.8 \pm 0.2^{\mathrm{a}, \mathrm{b}, \mathrm{cd}}$ & $45.6 \pm 1.8^{\mathrm{a}}$ & $4.7 \pm 0.2^{\mathrm{a}}$ \\
\hline
\end{tabular}

Table 2. Physicochemical characteristics of enrofloxacin-loaded docosanoic acid SLNs with different concentration of dimethyldioctadecyl ammonium chloride (mean \pm S.D., $\mathbf{n}=3$ ). DDAC: Dimethyldioctadecyl ammonium chloride; EE: Encapsulation efficiency; LC: Loading capacity; MD: Mean diameter; PDI: Polydispersity

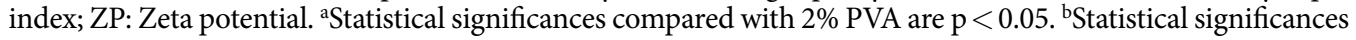

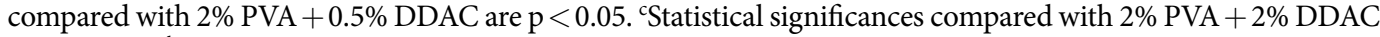
are $\mathrm{p}<0.05$. ${ }^{\mathrm{d}}$ Statistical significances compared with $2 \% \mathrm{PVA}+3 \%$ DDAC are $\mathrm{p}<0.05$.

A

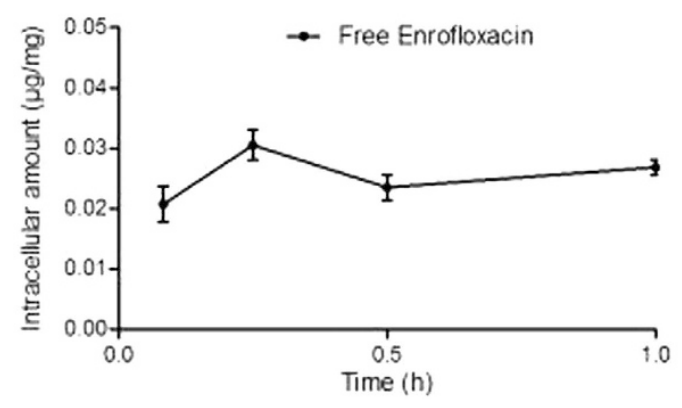

$\mathrm{B}$

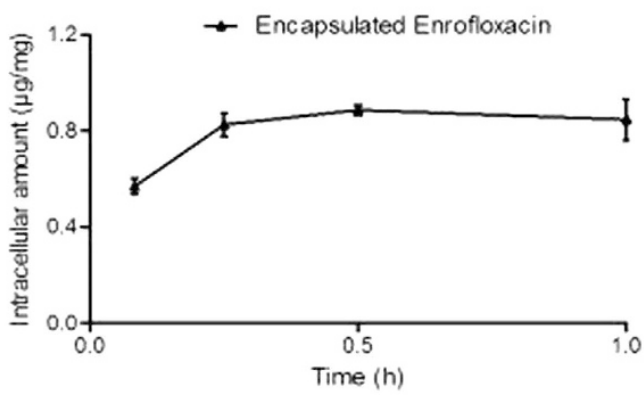

Figure 2. The cellular uptake kinetics of enrofloxacinin RAW.264.7 cells. (A) Free enrofloxacin; (B) Docosanoic acid encapsulated enrofloxacin. The enrofloxacin-loaded SLNs of $415 \mathrm{~nm}$ and $-22.1 \mathrm{mv}$ were prepared with $0.2 \mathrm{~g}$ enrofloxacin, $1.8 \mathrm{~g}$ fatty acid and $20 \mathrm{ml} 2 \%$ PVA.

of $501.3 \mathrm{~nm}$ was the same as that of $-8.1 \mathrm{mv}$ SLNs of $532.1 \mathrm{~nm}$ in size (Fig. 4). These results demonstrated that the net charge, rather than whether the charge was positive or negative, influenced the intracellular delivery of docosanoic acid SLN-encapsulated enrofloxacin. In addition, the intracellular content of $7.1 \mathrm{mv}$ docosanoic acid nanoparticles of $501.3 \mathrm{~nm}$ in size was 2.35 times higher than that of $18.8 \mathrm{mv}$ SLNs of $345.2 \mathrm{~nm}$ in size (Fig. 5), which suggested that particle size played a more important role than zeta potential in cellular uptake.

Intracellular elimination of encapsulated enrofloxacin. The intracellular elimination of optimum (605 $\mathrm{nm}$ and $-24.9 \mathrm{mv}$ ) docosanoic acid SLN-encapsulated enrofloxacin was determined by removing the 


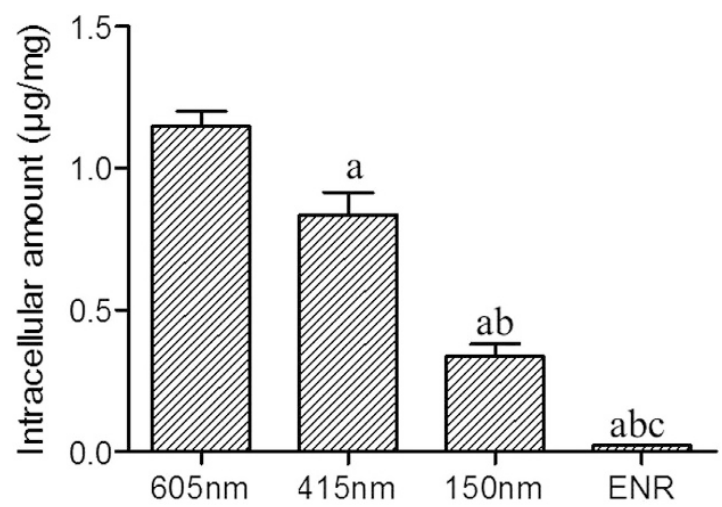

Figure 3. Effect of size on the uptake of docosanoic acid SLNs entrapped enrofloxacin in RAW.264.7 cells.

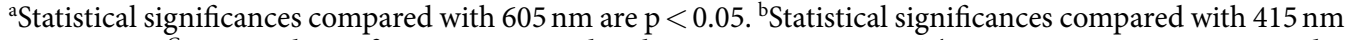
are $\mathrm{p}<0.05$. ${ }^{\mathrm{C} S t a t i s t i c a l}$ significances compared with $150 \mathrm{~nm}$ are $\mathrm{p}<0.05$. The $605 \mathrm{~nm}$ SLNs were prepared with $0.2 \mathrm{~g}$ enrofloxacin, $1.8 \mathrm{~g}$ docosanoic acid and $10 \mathrm{ml} 1 \%$ PVA by using $3 \mathrm{~mm}$ sonication probes with $60 \%$ amplitude. The $415 \mathrm{~nm}$ SLNs were prepared with $0.2 \mathrm{~g}$ enrofloxacin, $1.8 \mathrm{~g}$ docosanoic acid, and $20 \mathrm{ml} 2 \%$ PVA by using $6 \mathrm{~mm}$ sonication probes with $60 \%$ amplitude. The $150 \mathrm{~nm}$ SLNs were prepared with $0.2 \mathrm{~g}$ enrofloxacin, $1.8 \mathrm{~g}$ docosanoic acid, and $30 \mathrm{ml} 4 \%$ PVA by using $30 \mathrm{~mm}$ sonication probes with $80 \%$ amplitude.

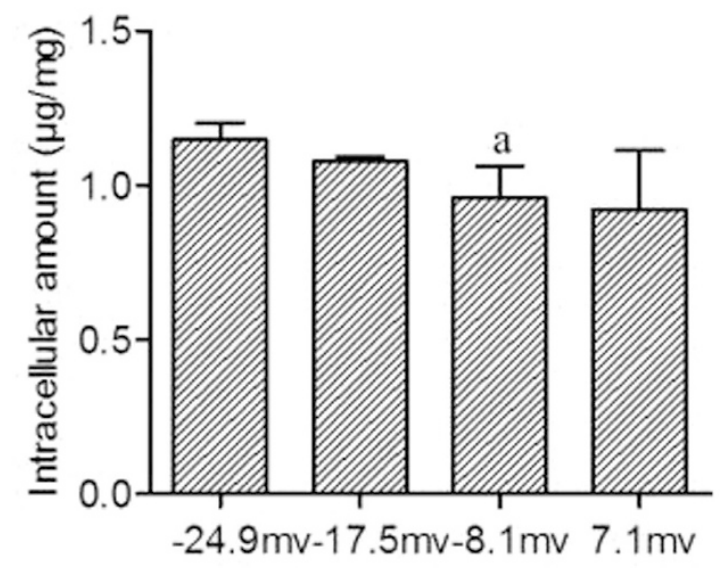

Figure 4. Effect of zeta potential on the uptake of docosanoic acid SLNs with similar sizes entrapped enrofloxacin in RAW.264.7 cells. The $-24.9 \mathrm{mv}$ SLNs were prepared with $0.2 \mathrm{~g}$ enrofloxacin, $1.8 \mathrm{~g}$ docosanoic acid, and $10 \mathrm{ml} 1 \%$ PVA. The $-17.5 \mathrm{mv}$ SLNs were prepared with $0.2 \mathrm{~g}$ enrofloxacin, $1.8 \mathrm{~g}$ docosanoic acid, and $20 \mathrm{ml} \%$ PVA and $0.5 \%$ DDAC. The $-8.1 \mathrm{mv}$ SLNs were prepared with $0.2 \mathrm{~g}$ enrofloxacin, $1.8 \mathrm{~g}$ docosanoic acid, and $20 \mathrm{ml} \mathrm{2 \%} \mathrm{PVA} \mathrm{and} \mathrm{2 \%} \mathrm{DDAC.} \mathrm{The} 7.1 \mathrm{mv}$ SLNs with $501 \mathrm{~nm}$ were prepared with $0.2 \mathrm{~g}$ enrofloxacin,

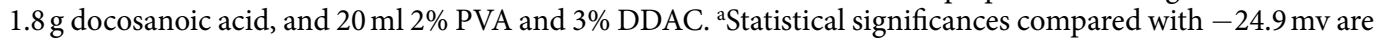
$\mathrm{p}<0.05$.

extracellular drug after exposure to the RAW 264.7 cells for $0.5 \mathrm{~h}$. The intracellular content of free enrofloxacin decreased by $53.87 \%$ and $78.57 \%$ after 0.5 and $1 \mathrm{~h}$, respectively, while the docosanoic acid SLN-encapsulated enrofloxacin was only reduced by $27.53 \%$ and $46.72 \%$ (Fig. 6). After incubation for $2 \mathrm{~h}$, the intracellular encapsulated drug remained at a concentration of $0.423 \mu \mathrm{g} / \mathrm{mg}$, while the free drugs were no longer detectable in the cells. These results showed that the docosanoic acid SLNs' payload of enrofloxacin was eliminated from the cells much more slowly than the free drug.

The activity of SLN-encapsulated enrofloxacin against intracellular Salmonella. Enrofloxacinloaded docosanoic acid SLNs of $605 \mathrm{~nm}$ and $-24.9 \mathrm{mv}$ were more effective against intracellular Salmonella CVCC541 than free enrofloxacin at three different concentrations: $0.06,0.24$ and $0.6 \mu \mathrm{g} / \mathrm{mL}$. The $0.24 \mu \mathrm{g} / \mathrm{mL}$ encapsulated enrofloxacin exhibited stronger antibacterial activity than $0.6 \mu \mathrm{g} / \mathrm{mL}$ free enrofloxacin throughout the incubation period. As the incubation time increased, the inhibitory effect of docosanoic acid SLN-encapsulated enrofloxacin was more significant than free enrofloxacin (Fig. 7). At $48 \mathrm{~h}$, the intracellular colony logarithmic value of the $0.6 \mu \mathrm{g} / \mathrm{mL}$ free enrofloxacin group ( 4.15 colony forming units (CFU)/ $\mathrm{mL}$ ) was greater than that of the $0.06 \mu \mathrm{g} / \mathrm{mL}$ encapsulated enrofloxacin group $(3.80 \mathrm{CFU} / \mathrm{mL})$. The $0.6 \mu \mathrm{g} / \mathrm{mL}$ 


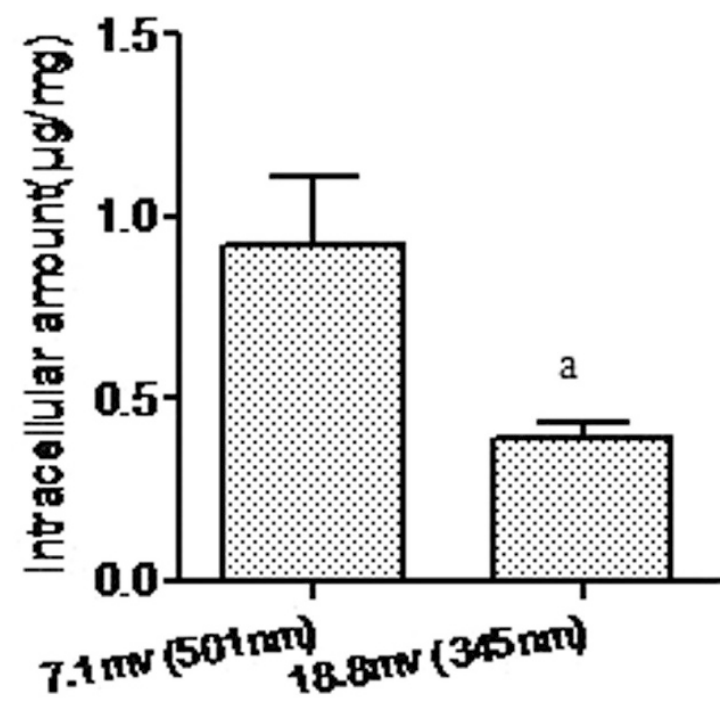

Figure 5. The uptake of different zeta potential and size docosanoic acid SLNs entrapped enrofloxacin in RAW.264.7 cells. The SLNs with $7.1 \mathrm{mv}$ and $501 \mathrm{~nm}$ were prepared with $0.2 \mathrm{~g}$ enrofloxacin, $1.8 \mathrm{~g}$ docosanoic acid, and $20 \mathrm{ml} 2 \%$ PVA and 3\% DDAC. The SLNs with $18.8 \mathrm{mv}$ and $345 \mathrm{~nm}$ were prepared with $0.2 \mathrm{~g}$ enrofloxacin, $1.8 \mathrm{~g}$ docosanoic acid, and $20 \mathrm{ml} \%$ PVA and $4 \%$ DDAC. ${ }^{a}$ Statistical significances compared with $7.1 \mathrm{mv}$ are $\mathrm{p}<0.05$.

A

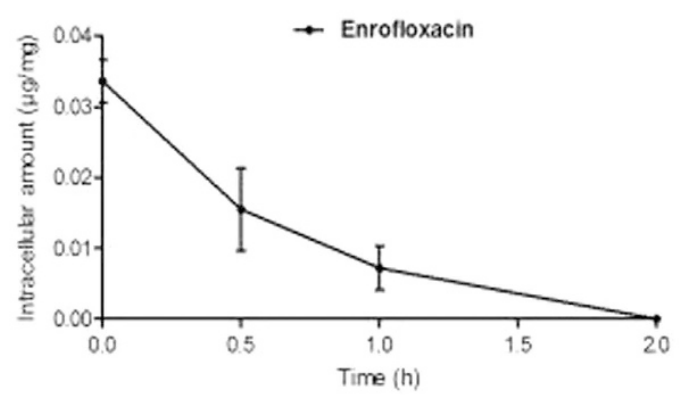

B

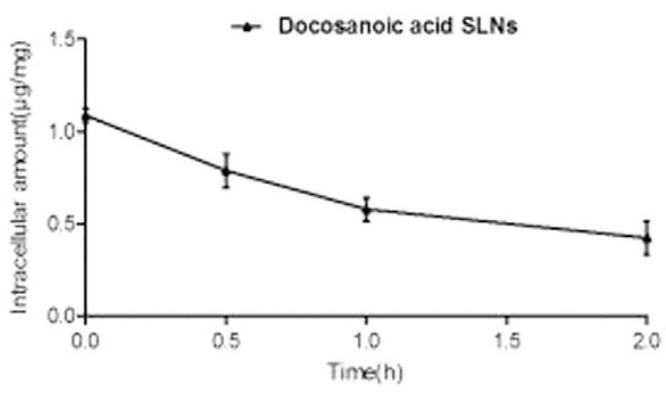

Figure 6. The intracellular elimination kinetics of enrofloxacin. (A) Free enrofloxacin; (B) Docosanoic acid encapsulated enrofloxacin. The enrofloxacin-loaded SLNs with $605 \mathrm{~nm}$ and $-24.9 \mathrm{mv}$ were prepared with $0.2 \mathrm{~g}$ enrofloxacin, $1.8 \mathrm{~g}$ fatty acid and $20 \mathrm{ml} \%$ PVA.

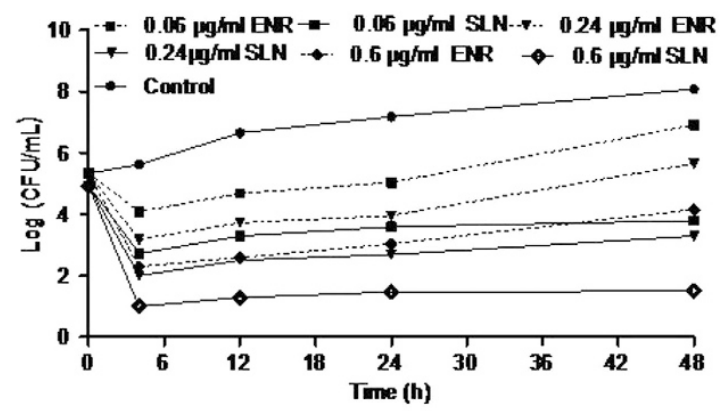

Figure 7. Inhibition curve of enrofloxacin and docosanoic acid SLN entrapped enrofloxacin against intracellular salmonella CVCC541. ENR: Free enrofloxacin; DAS: Docosanoic acid SLNs. The enrofloxacinloaded SLNswith $605 \mathrm{~nm}$ and $-24.9 \mathrm{mv}$ were prepared with $0.2 \mathrm{~g}$ enrofloxacin, $1.8 \mathrm{~g}$ fatty acid and $10 \mathrm{ml} 1 \%$ PVA.

encapsulated enrofloxacin could decrease the intracellular bacteria by $99.97 \%$, thus reaching the minimum bactericidal concentration. 


\section{Discussion}

The strong antibacterial potency and efficient permeation of enrofloxacin into cells makes it an appealing choice for the treatment of infections caused by Salmonella, but it always fails to completely eradicate intracellular Salmonella infection in animals due to its rapid efflux from cells when the extracellular concentration falls ${ }^{6,16,17}$. In order to enhance the intracellular delivery of this drug, enrofloxacin-loaded docosanoic acid SLNs were prepared and examined in this study. The docosanoic acid SLN-encapsulated enrofloxacin rapidly reached a much higher maximum intracellular concentration than the free enrofloxacin. The docosanoic acid SLNs were 27.0637.71 times more efficient in the delivery of their enrofloxacin payload into RAW 264.7 cells than the free drug, although the rapid equilibration of the free drug within the cells suggests that the plasma membrane does not present a huge barrier to enrofloxacin penetration. The significant increase in intracellular accumulation will increase the efficacy of encapsulated enrofloxacin relative to the free drug.

A growing body of research demonstrates that the properties of nanoparticles can affect their uptake and that of their encapsulated antimicrobial agents ${ }^{14}$. Docosanoic acid SLNs of different sizes and zeta potentials were prepared by the adjustment of ultrasonic power, ultrasonic time, and the type and concentration of surfactant used. These variations were used to find the common and decisive factors of docosanoic acid nanoparticles in mediating their cellular uptake and thus to maximize intracellular accumulation of encapsulated enrofloxacin. The size of nanoparticles was found to significantly affect the cellular uptake of docosanoic acid SLN-encapsulated enrofloxacin. The intracellular concentrations were significantly enhanced when size was increased from 150 to $605 \mathrm{~nm}$, which might be due to the fact that cellular uptake of nanoparticles in phagocytes predominantly depends on phagocytosis when their size increases beyond $100 \mathrm{~nm}^{14}$. In most cases, the phagocytosis rate of polymeric nanoparticles and liposomes is enhanced when particle size increases over the range of $100-1000 \mathrm{~nm}$ and becomes constant at over $1000 \mathrm{~nm}^{13,14,18,19}$. Therefore, the PDI of docosanoic acid SLNs, which reflects the uniformity of nanoparticle sizes, should be as low as possible in the preparation process.

The surface charge of docosanoic acid nanoparticles was also found to be an important factor in determining the uptake behavior of their encapsulated drugs, although whether the charge was positive or negative did not have an effect. For the three different anionic docosanoic acid SLNs, the cellular uptake of enrofloxacin was positively correlated with the net charge of the nanoparticles. This is consistent with other reports that the cellular accumulation of azithromycin and ciprofloxacin increased in proportion to the liposomal negative charge ${ }^{20,21}$. The preferential cellular uptake of highly negatively charged nanoparticles is probably due to the high charge density areas at the cell surface, which can mediate the non-specific interactions with non-specific receptors by electrostatic interactions ${ }^{22}$, especially with the type B scavenger receptor ${ }^{23}$. The higher intracellular content of docosanoic acid nanoparticles of $7.1 \mathrm{mv}$ and $501.3 \mathrm{~nm}$ than the SLNs of $18.8 \mathrm{mv}$ and $345.2 \mathrm{~nm}$ may indicate that size is a more important factor than zeta potential in determining the cellular uptake efficacy of docosanoic acid SLNs. According to the above results, the docosanoic acid SLNs of $605 \mathrm{~nm}$ and $-24.9 \mathrm{mv}$ were the optimal carriers for intracellular delivery. The intracellular elimination rate of the optimal docosanoic acid nanoparticle-encapsulated enrofloxacin was also significantly slower than the free enrofloxacin.

The enhanced cellular uptake and intracellular retention of encapsulated enrofloxacin suggests that enrofloxacin-loaded docosanoic acid SLNs might be highly effective against intracellular Salmonella. Therefore, an intracellular infection with Salmonella CVCC541 was established to evaluate the selected SLNs. The time-bactericidal curve demonstrated that enrofloxacin-loaded docosanoic acid SLNs displayed 2.5-10 times more effective inhibition against intracellular Salmonella CVCC541 than free enrofloxacin at the three concentrations: minimal inhibitory concentration (MIC) $(0.06 \mu \mathrm{g} / \mathrm{mL}), 4 \mathrm{MIC}(0.24 \mu \mathrm{g} / \mathrm{mL})$ and $10 \mathrm{MIC}(0.6 \mu \mathrm{g} / \mathrm{mL})$ against Salmonella CVCC541. The increase in antibacterial efficacy was not as significant as the increase in the intracellular concentration of the drug. This might be because a substantial portion of the intracellular drug remained associated with the nanoparticles and was sequestered away from the intracellular bacteria ${ }^{24}$. These results are essentially better than other reports in which ciprofloxacin and moxifloxacin bounded to poly (isobutyl cyanoacrylate) and poly (butyl cyanoacrylate) nanoparticles exhibited similar activity to free drugs ${ }^{24,25}$.

As the encapsulated enrofloxacin in cells was released from the nanoparticles, the antibacterial effect of enrofloxacin-loaded docosanoic acid SLNs became more pronounced than that of the free drug as the incubation time increased. When the incubation time increased up to $48 \mathrm{~h}$, the intracellular colony $(3.80 \mathrm{CFU} / \mathrm{mL})$ of the $0.06 \mu \mathrm{g} / \mathrm{mL}$ encapsulated enrofloxacin group was smaller than that $(4.15 \mathrm{CFU} / \mathrm{mL})$ of the $0.6 \mu \mathrm{g} / \mathrm{mL}$ free enrofloxacin group. It is particularly interesting that $0.6 \mu \mathrm{g} / \mathrm{mL}$ docosanoic acid SLN-encapsulated enrofloxacin inhibited $99.97 \%$ Salmonella growth at $48 \mathrm{~h}$, while the $0.6 \mu \mathrm{g} / \mathrm{mL}$ free enrofloxacin did not inhibit the growth of bacteria during the same experimental period. All of these results indicate that enrofloxacin-loaded docosanoic acid SLNs might be a promising formulation for intracellular Salmonella infection therapy. The docosanoic acid SLNs, especially those with a larger size and higher charge, could also be a promising carrier for treating other intracellular bacteria infections.

\section{Materials and Methods}

Materials. Enrofloxacin of reference standard was purchased from the China Institute of Veterinary Drug Control (Beijing, China). Native enrofloxacin was bought from Wuhan Konglong Century Technology Development Co., Ltd. (Wuhan, China). Docosanoic acid and dimethyldioctadecyl ammonium chloride (DDAC) were purchased from Shanghai Aladdin Biochemical Polytron Technologies Inc. (Shanghai, China). Polyvinyl alcohol (PVA) was obtained from Sigma (St. Louis, MO, USA). Methyl alcohol and acetonitrile with high performance liquid chromatography (HPLC) grade were purchased from Tedia (Ohio, USA). The water for HPLC was prepared with a Milli-Q system (Millipore, Bedford, MA, USA). RAW 264.7 cell lines were obtained from the National Veterinary Drug Residues Reference Laboratory of Huazhong Agricultural University (Wuhan, China). Dulbecco's modified eagle medium (DMEM, $4.5 \mathrm{~g} / \mathrm{L}$ of glucose), Dulbecco's modified eagle medium/Ham's F-12 mixture (DMEM/F12), penicillin $(100 \mathrm{U} / \mathrm{mL})$-streptomycin $(100 \mathrm{mg} / \mathrm{mL})$ and fetal bovine serum (FBS) were 
purchased from Hyclone Co., Ltd. (Logan City, USA). Radio immunoprecipitation assay (RIPA) cell lysis solution was bought from Shanghai Ruji Biology Technology Co., Ltd. (Shanghai, China). All other reagents and solvents not specified in the text were of analytical grade and commercially available.

Preparation of enrofloxacin-loaded docosanoic acid SLNs. Enrofloxacin-loaded SLNs were prepared using a hot homogenization and ultrasonication method ${ }^{15}$. The different sizes and zeta potentials of docosanoic acid SLNs were obtained by adjusting the preparation process and the type, concentration and volume of the surfactant. Briefly, $1.8 \mathrm{~g}$ docosanoic acid and $0.2 \mathrm{~g}$ enrofloxacin were added to a $50 \mathrm{~mL}$ tube and put in a boiling water bath. After the drug was dissolved in the melted lipid matrix, different volumes $(10,20$ or $30 \mathrm{~mL})$ of 1,2 or $4 \%$ PVA solution, with or without DDAC solution at concentrations of $0.5,2,3$ or $4 \%$, were preheated in a boiling water bath and poured into the lipid phase under magnetic stirring. The mixture was then sonicated for 8 min using 3, 6 or $30 \mathrm{~mm}$ microprobes with $60 \%$ or $80 \%$ amplitude (VCX 130 Vibra-CellTM, Sonics \& Materials, Inc., Newtown, CT, USA) to form a nanoemulsion. The hot nanoemulsion was poured into a certain volume of cold water to obtain a nanoparticle suspension. The nanoparticles were collected by centrifugation at $14,000 \mathrm{rpm}$ (Hitachi Centrifugation CR21G; Hitachi Koki Co., Ltd., Japan) for $60 \mathrm{~min}$ at $4{ }^{\circ} \mathrm{C}$, and washed three times with distilled water. The SLNs were suspended in $10 \mathrm{~mL}$ distilled water and lyophilized for $48 \mathrm{~h}$ (Freeze Dry System; Labconco, USA).

Atomic force microscopy (AFM). The morphology of nanoparticles of different sizes was measured using an Aglient 5500 AFM (Agilent Technologies, AZ, USA) under normal atmospheric conditions. In brief, $20 \mathrm{mg}$ samples were suspended in $500 \mu \mathrm{L}$ distilled water and $2 \mu \mathrm{L}$ of the suspension was placed on a cover glass. After oven-drying at room temperature, imaging of the samples was performed in contact mode with pyramidal silicon nitride tips.

Determination of loading capacity and encapsulation efficiency. To determine the enrofloxacin content of the nanoparticles, $10 \mathrm{mg}$ freeze-dried SLNs was added to a $15 \mathrm{~mL}$ tube containing $10 \mathrm{~mL}$ acetonitrile/ water solution $(\mathrm{v} / \mathrm{v} ; 1: 1)$ and put in a boiling water bath for $20 \mathrm{~min}$ to destroy the nanoparticles so that the drug was completely released. The nanoparticle suspension after heating was added to the volume of $10 \mathrm{~mL}$ and centrifuged at 8,000 rpm (Hitachi Centrifugation CR21G; Hitachi Koki Co., Ltd., Japan) for $10 \mathrm{~min}$. The supernatant was diluted 100-fold and injected into Waters 2695 series HPLC equipped with a UV detector (Waters Corp., Milford, MA, USA) for analysis after filtration. The assay was repeated three times using different samples from independent preparations. The loading capacity (LC) and encapsulation efficiency (EE) were defined as follows:

$$
\mathrm{LC}(\%)=[(\text { Weight of enrofloxacin in SLNs }) /(\text { Weight of SLNs })] \times 100
$$

$$
\mathrm{EE}(\%)=[(\text { Weight of enrofloxacin in SLNs }) /(\text { Weight of enrofloxacin added })] \times 100
$$

Determination of size, polydispersity index (PDI) and zeta potential. The size, PDI and zeta potential of different enrofloxacin-loaded SLNs were measured by photon correlation spectroscopy (PCS) by using Zetasizer ZX3600 (Malvern Instruments, UK) at $25^{\circ} \mathrm{C}$. The samples were suspended in distilled water by ultrasonication for $5 \mathrm{~s}$ at $0{ }^{\circ} \mathrm{C}$ to remove the air bubbles and break up the agglomerates. The concentration of the sample was $2.7 \mathrm{mg} / \mathrm{mL}$ for the tests of size and PDI, and $0.3 \mathrm{mg} / \mathrm{mL}$ for the test of zeta potential, in order to get the optimum kilo counts per second of 20-400 for the measurements ${ }^{14}$. All measurements were repeated in triplicate by using different samples from independent preparations.

Cell culture. The RAW 264.7 cells were grown in culture flasks (Corning Costar Co., Ltd., NY, USA) containing DMEM supplemented with $10 \%(\mathrm{v} / \mathrm{v})$ FBS, $1 \%(\mathrm{v} / \mathrm{v})$ L-Glutamine solution and $1 \%(\mathrm{v} / \mathrm{v})$ penicillin-streptomycin, at $37^{\circ} \mathrm{C}$ in an ambient atmosphere with $5 \% \mathrm{CO}_{2}$. For routine maintenance, the cell medium was changed every $24 \mathrm{~h}$ and the cells were sub-cultured with $0.25 \%$ trypsin $-0.02 \%$ ethylene diamine tetraacetic acid (EDTA) solution after reaching $80-90 \%$ confluence.

Determination of cellular uptake of encapsulated enrofloxacin. For the cellular uptake experiment, the cells were seeded at $1 \times 10^{5}$ cells $/ \mathrm{cm}^{2}$ onto 6 -well culture plates in volumes of $2 \mathrm{~mL}$. When the cells reached about $80-90 \%$ confluence, the medium was replaced with $\mathrm{pH} 7.4$ Hanks' balanced salt solution (HBSS) and the cells were pre-incubated at $37^{\circ} \mathrm{C}$ for $1 \mathrm{~h}$. After pre-incubation, the cells were incubated with $2 \mathrm{~mL}$ fresh incubation medium containing $10 \mu \mathrm{g} / \mathrm{mL}$ free enrofloxacin or different sizes and zeta potentials of docosanoic acid SLN-encapsulated enrofloxacin for $0.083,0.25,0.5$ and $1 \mathrm{~h}$. The surface of RAW 264.7 cells was quickly rinsed three times with Phosphate buffer (PBS) at $4{ }^{\circ} \mathrm{C}$ to remove the extracellular drug. The washed cells were lysed using $150 \mu \mathrm{L}$ RIPA cell lysis solutions and collected with $1 \mathrm{~mL}$ deionized water for each well. The collected cells were sonicated with an ultrasonic cell disruption system (VCX130; Sonics \& Materials, Inc., USA) for $30 \mathrm{~s}$. Subsequently, $5 \mu \mathrm{L}$ cell lysate was used to detect the protein content with the bicinchoninic acid (BCA) method. The remainder of the cell lysate was deproteinized using $1 \mathrm{~mL}$ methanol under vortex mixing for $2 \mathrm{~min}$ and centrifugation at $12,000 \mathrm{rpm}$ for $15 \mathrm{~min}$ at $4^{\circ} \mathrm{C}$. The supernatant was evaporated to dryness under a nitrogen evaporator (N-EVAP112; Organomation Associates Inc., USA) at $30^{\circ} \mathrm{C}$. The concentrates were dissolved with $500 \mu \mathrm{L}$ mobile phase and injected into HPLC vials for analysis with a fixed injection volume of $40 \mu \mathrm{L}$.

Determination of intracellular elimination of encapsulated enrofloxacin. To determine the intracellular drug elimination process, the confluent RAW 264.7 cells in each well of the 6-well culture 
plates were exposed to $10 \mu \mathrm{g} / \mathrm{mL}$ free enrofloxacin and docosanoic acid SLN-encapsulated enrofloxacin (in SLNs of $605 \mathrm{~nm}$ and $-24.9 \mathrm{mv}$ ) for $0.5 \mathrm{~h}$. Afterwards, the medium (without FBS, L-Glutamine solution and penicillin-streptomycin) containing enrofloxacin was replaced by the blank basic medium and the cells continued to incubate. After continued incubation for $0.5,1$, and $2 \mathrm{~h}$, the cell surface was quickly rinsed with $4^{\circ} \mathrm{C}$ PBS three times to remove the extracellular drug, and the intracellular enrofloxacin was measured by HPLC.

Determination of enrofloxacin and protein levels. Enrofloxacin was determined using a Waters 2695 series HPLC and a Waters 2587 UV detector set at a wavelength of $278 \mathrm{~nm}$. The chromatographic separation was achieved with an analytical ZORBAX SB-2 $\mathrm{C}_{18}$ column $(250 \times 4.6 \mathrm{~mm}$, i.d. $5 \mu \mathrm{m}$; Agilent Technology, USA $)$ at $30^{\circ} \mathrm{C}$. The mobile phase was acetonitrile and $0.1 \%$ formic acid solution with the proportion of $14 / 86(\mathrm{v} / \mathrm{v})$ and a flow rate of $1.0 \mathrm{~mL} / \mathrm{min}$. The working curve for the uptake experiment was $\mathrm{y}=189.72 \times-902.22$ over the concentration range of $40-1000 \mu \mathrm{g} / \mathrm{L}\left(\mathrm{r}^{2}=0.9994\right)$. The recovery of the three different concentrations $(40,500$ and $1000 \mu \mathrm{g} / \mathrm{L}$ ) was $88.2 \%, 93.6 \%$ and $97.5 \%$ respectively, from RAW 264.7 lysate. The intra-day and inter-day relative standard deviations (RSD) were lower than 7\%. The limit of detection (LOD) and quantification (LOQ) were 20 and $40 \mu \mathrm{g} / \mathrm{L}$, respectively.

The protein concentration was measured using a bicinchoninic acid (BCA) protein assay kit with bovine serum albumin (BSA) as the standard. In brief, after centrifugation, $5 \mu \mathrm{L}$ cell lysate was added to $200 \mu \mathrm{L}$ BCA reagents in 96-well plates and the absorbance was read at $562 \mathrm{~nm}$ with a Multiskan spectrum microplate reader (Elx800; Bio-tek instrument, Inc., USA). The BSA linear equation was $y=0.8984 \times+0.1229$ over the linear range of $0.025-0.5 \mathrm{mg} / \mathrm{mL}\left(\mathrm{r}^{2}=0.9994\right)$.

Determination of the activity of encapsulated enrofloxacin against intracellular. Salmonella. To determine the antimicrobial effect of enrofloxacin against intracellular bacteria, RAW 264.7 cells in 24-well culture plates $\left(10^{6}\right.$ cells per well) were infected with $10^{7} \mathrm{CFU} / \mathrm{mL}$ of Salmonella CVCC541 for $1 \mathrm{~h}$. Afterwards, the medium containing bacteria was removed and the cells were incubated with $0.5 \mathrm{~mL}$ of $100 \mu \mathrm{g} / \mathrm{mL}$ gentamicin for $0.5 \mathrm{~h}$ to completely kill the extracellular bacteria. Extracellular gentamicin was removed with $4{ }^{\circ} \mathrm{C} \mathrm{PBS}$ three times and the cells were incubated with DMEM basic medium for $4 \mathrm{~h}$ to establish the infection model. Nanoparticles of $605 \mathrm{~nm}$ and $-24.9 \mathrm{mv}$ with encapsulated or free enrofloxacin of $0.06,0.24$ and $0.6 \mu \mathrm{g} / \mathrm{mL}$ were added to the cultures and remained there for $0,4,12,24$ and $48 \mathrm{~h}$. At fixed time points, the extracellular bacteria were removed by three consecutive washes with $\mathrm{PBS}$ at $4^{\circ} \mathrm{C}$, and the intracellular viable Salmonella counts $(\mathrm{CFU} / \mathrm{mL})$ were performed by plating serial dilutions of the cell lysates and counting the number of colonies after incubation at $37^{\circ} \mathrm{C}$ for $24 \mathrm{~h}$. The time-kill curve was created by plotting average counts as a function of time.

Statistical Analysis. Data were expressed as mean \pm S.D. and assessed using one-way analysis of variance (ANOVA) by GraphPad Prism. Significance was evaluated at $p$-value of 0.05 , respectively.

\section{References}

1. Haraga, A., Ohlson, M. B. \& Miller, S. I. Salmonellae interplay with host cells. Nature Reviews Microbiology 6, 53-66 (2008).

2. Hale, C. R. et al. Estimates of enteric illness attributable to contact with animals and their environments in the United States. Clin. Infect. Dis. 54 (Suppl 5), S472-479 (2012).

3. Imanishi, M. et al. Salmonellosis and Meat Purchased at Live-Bird and Animal-Slaughter Markets, United States, 2007-2012. Emerg. Infect. Dis. 20(1), 167-169 (2014).

4. Lahiri, A., Iyer, N., Das, P. \& Chakravortty, D. Visiting the cell biology of salmonella infection. Microbes. Infect. 12, 809-818 (2010).

5. Briones, E., Colino, C. I. \& Lanao, J. M. Delivery systems to increase the selectivity of antibiotics in phagocytic cells. Journal of Controlled Release 125(3), 210-227 (2008).

6. Schoevers, E. J., Vanleengoed, L. A. M. G., Verheijden, J. H. M. \& Niewold, T. A. Effects of Enrofloxacin on Porcine Phagocytic Function. Antimicrob. Agents. Chemother. 43(9), 2138-2143 (1999).

7. Baș, A. L., Şimșek, A., Corlu, M., Elmas, M. \& Değim, Z. G. Determination of intracellular concentrations of free and two types of liposome-encapsulated enrofloxacin in Anatolian shepherd dog monocytes. J. Vet. Med. B 49, 289-293 (2002).

8. Bas, A. L., Simsek, A., Erganis, O. \& Corlu, M. Efficacies of liposome-encapsulated enrofloxacin against Staphylococcus aureus infection in Anatolian shepherd dog monocytes in vitro. DTW. Deutsche Tierarztliche Wochenschrift 112, 219-223 (2005).

9. Deĝim, Z. Deĝim, T., Bas, L. \& Elmas, M. The use of liposomal enrofloxacin for intracellular infections in Kangal dogs and visualization of phagocytosis of liposomes. Journal of biomedical materials research 61(2), 246-251 (2002).

10. Bas, A. L. et al. Efficacies of free and liposome-encapsulated enrofloxacin (Baytril ${ }^{\circledR}$ ) against Staphylococcus aureus infection in Turkish shepherd dog neutrophils in vitro. Rev. Med. Vet. 151, 415-420 (2000).

11. Akbari, V., Abedi, D., Pardakhty, A. \& Sadeghi-Aliabadi, H. Ciprofloxacin nano-niosomes for targeting intracellular infections: an in vitro evaluation. Journal of nanoparticle research 15(4), 1-14 (2013).

12. Chono, S., Tanino,T., Seki, T. \& Morimoto, K. Efficient drug delivery to alveolar macrophages and lung epithelial lining fluid following pulmonary administration of liposomal ciprofloxacin in rats with pneumonia and estimation of its antibacterial effects. Drug Dev. Ind. Pharm. 34, 1090-1096 (2008).

13. Chono, S., Tanino, T., Seki, T. \& Morimoto, K. Uptake characteristics of liposomes by rat alveolar macrophages: influence of particle size and surface mannose modification. J. Pharm. Pharmacol. 59, 75-80 (2007).

14. Xie, S. Y. et al. Biodegradable nanoparticles for intracellular delivery of antimicrobial agents. J. Control Release 187, 101-117 (2014).

15. Xie, S. Y. et al. Preparation, characterization and pharmacokinetics of enrofloxacin-loaded solid lipid nanoparticles: influences of fatty acids. Colloids and Surfaces B: Biointerfaces 83(2), 382-387 (2011).

16. Delsol, A. A., Woodward, M. J. \& Roe, J. M. Effect of a 5 day enrofloxacin treatment on Salmonella enterica serotype Typhimurium DT104 in the pig. Antimicrob. Chemother. 54, 692-693 (2004).

17. Boeckh, A., Boothe, D., Wilkie, S. \& Jones, S. Time Course of Enrofloxacin and Its Active Metabolite in Peripheral Leukocytes of Dogs. Vet. Ther. 2(4), 334-344 (2001).

18. Hillaireau, H. \& Couvreur, P. Nanocarriers' entry into the cell: relevance to drug delivery. Cell. Mol. Life Sci. 66, 2873-2896 (2009).

19. Chono, S., Tanino, T., Seki, T. \& K. Morimoto. Influence of particle size on drug delivery to rat alveolar macrophages following pulmonary administration of ciprofloxacin incorporated into liposomes. J. Drug Target. 14, 557-566 (2006).

20. Tabata, Y. \& Ikada, Y. Effect of the size and surface charge of polymer microspheres on their phagocytosis by macrophage. Biomaterials 9, 356-362 (1988). 
21. Oh, Y. K., Nix, D. E. \& Straubinger, R. M. Formulation and efficacy of liposome-encapsulated antibiotics for therapy of intracellular Mycobacterium avium infection. Antimicrob. Agents Chemother. 392, 104-2111 (1995).

22. Schwendener, R. A., Lagocki, P. A. \& Rahman, Y. E. The effects of charge and size on the interaction of unilamellar liposomes with macrophages. Biochim. Biophys Acta. 772, 93-101 (1984).

23. Rigotti, A., Acton, S. L. \& Krieger, M. The class B scavenger receptors SR-BI and CD36 are receptors for anionic phospholipids. J. Biol. Chem. 270 16221-16224 (1995).

24. Kisich, K. O. et al. Encapsulation of moxifloxacin within poly (butyl cyanoacrylate) nanoparticles enhances efficacy against intracellular Mycobacterium tuberculosis. International Journal of Pharmaceutics, 345, 154-162 (2007).

25. Fawaz, F., Bonini, F. \& Maugein, J. Ciprofloxacin-loaded polyisobutylcyanoacrylate nanoparticles: pharmacokinetics and in vitro antimicrobial activity. Int. J. Pharm. 168, 255-259 (1998).

\section{Acknowledgements}

This work was supported by the National Natural Science Foundation of China (31302140), National key research and development program of china (2016YFD0501310), and Risk Assessment of unknown and known hazard factors of livestock and poultry products (GJFP2017008).

\section{Author Contributions}

Xie, S.Y. designed experiments and wrote manuscript. Yang, F. carried out nanoparticles preparation and cell experiment, and wrote manuscript. Pan, Y.H. designed experiments and edited manuscript. Yuan, Z.H. designed experiments and edited manuscript. Tao, Y.F. carried out drug determination. Chen, D.M. carried out drug determination. Qu, W. took part in design of nanoparticles formulation. Huang, L.L. carried out statistical analyses. Liu, Z.L. carried out statistical analyses.

\section{Additional Information}

Competing financial interests: The authors declare no competing financial interests.

How to cite this article: Xie, S. et al. Enhanced intracellular delivery and antibacterial efficacy of enrofloxacinloaded docosanoic acid solid lipid nanoparticles against intracellular Salmonella. Sci. Rep. 7, 41104; doi: 10.1038/srep41104 (2017).

Publisher's note: Springer Nature remains neutral with regard to jurisdictional claims in published maps and institutional affiliations.

(c) (i) This work is licensed under a Creative Commons Attribution 4.0 International License. The images or other third party material in this article are included in the article's Creative Commons license, unless indicated otherwise in the credit line; if the material is not included under the Creative Commons license, users will need to obtain permission from the license holder to reproduce the material. To view a copy of this license, visit http://creativecommons.org/licenses/by/4.0/

(C) The Author(s) 2017 